\begin{abstract}
References
1. Balaji S, Daga A, Bradley DJ, Etheridge SP Law IH, Batra AS, et al. An international multicenter study comparing arrhythmia prevalence between the intracardiac lateral tunnel and the extracardiac conduit type of Fontan operations. $J$ Thorac Cardiovasc Surg. 2014;148:576-81.

2. Bartz PJ, Driscoll DJ, Dearani JA, Puga FJ, Danielson GK, O'Leary PW, et al. Early and late results of the modified Fontan operation for heterotaxy syndrome 30 years of experience in 142 patients. J Am Coll Cardiol. 2006;48:2301-5.

3. Dilawar M, Bradley SM, Saul JP, Stroud MR, Balaji S. Sinus node dysfunction after intraatria lateral tunnel and extracardiac conduit Fontan procedures. Pediatr Cardiol. 2003:24:284-8.

4. Kumar SP, Rubinstein CS, Simsic JM, Taylor AB Saul JP, Bradley SM. Lateral tunnel versus extracardiac conduit Fontan procedure: a concurrent comparison. Ann Thorac Surg. 2003;76:1389-96; discussion 1396-7.
\end{abstract}

http://dx.doi.org/10.1016/ j.jtcvs.2015.01.004

\section{LACK OF INFLUENCE OF HETEROTAXY ON ARRHYTHMIA PREVALENCE AFTER INTRACARDIAC VERSUS EXTRACARDIAC FONTAN OPERATIONS}

\section{Reply to the Editor:}

We thank Dr Rajanbabu for his comments. In response to these comments, we reanalyzed our cohort after removing the heterotaxy patients from both groups and the statistical results were the same. We therefore believe that the difference in the number of heterotaxy patients in the 2 groups did not influence our results.

We do, however, agree with his comment that transvenous pacing and transcatheter ablation are harder to perform after an extracardiac conduit operation. In light of our study results, the intracardiac tunnel may be the better operation from that point of view. Yet we caution that the followup in the 2 groups (particularly the extracardiac conduit cohort) in our study was short and that it may be wise to wait for longer follow-up before making definitive recommendations.

Seshadri Balaji, PhD, MBBS, $\operatorname{MRCP}(U K)^{a}$
Maully Shah, $M B B S^{b}$

${ }^{a}$ Oregon Health \& Science University

Portland, Ore

${ }^{b}$ Children's Hospital of Philadelphia

Philadelphia, $\mathrm{Pa}$

http://dx.doi.org/10.1016/

j.jtcvs.2014.12.044

\section{A RECOMMENDATION FOR MODIFICATION OF THE \\ HOURGLASS-SHAPED RESECTION TECHNIQUE FOR REPAIR OF TALL MITRAL VALVE POSTERIOR PROLAPSE} To the Editor:

We have read the article entitled "Hourglass-shaped resection technique for repair of tall mitral valve posterior prolapse" by Sawazaki and colleagues ${ }^{1}$ with great interest. They have well described their novel method for repairing a high posterior leaflet of the mitral valve. They have adopted triangular resection for a posterior leaflet of normal height, and an hourglass resection for an excessively high posterior leaflet without annular plication. This simple and reproducible method may indeed improve outcomes of folding plasty and avoid the sacrifice of large amounts of useful leaflet tissue during annular plication. ${ }^{2,3}$ Short-term results of this reproducible technique seem promising.

However, when the technical details for this novel method are examined more closely, some questions may arise. For instance, if points $B$ and $E$, which represent the midpoints of a posterior leaflet, were sutured to the annulus, as shown in Figure 1, such an approach has important drawbacks. We think that this maneuver may pull the annulus and cause narrowing of the leaflet width, resulting in a final shape that impedes formation of a new, normal-sized, and deeply coapted posterior scallop. Thus, we suggest that some refining modifications to improve this technique may aid in achievement of more satisfactory outcomes and decrease postoperative morbidity and complications.

Gökhan Ilhan, $M D^{a}$ Mert Kestelli, $M D^{b}$ Berkan Ozpak, $M D^{b}$ Sahin Bozok, MD

${ }^{a}$ Department of Cardiovascular Surgery

Recep Tayyip Erdogan University School of Medicine Rize, Turkey

${ }^{b}$ Department of Cardiovascular Surgery

Ataturk Training and Research Hospital Izmir, Turkey

\section{References}

1. Sawazaki M, Tomari S, Izawa N, Ueda Y Hourglass-shaped resection technique for repair of tall mitral valve posterior leaflet prolapse. J Thoracic Cardiovasc Surg. 2013;146:275-7.

2. Perier P, Clausnizer B, Mistarz K. Carpentier "sliding leaflet" technique for repair of the mitral valve: early results. Ann Thorac Surg. 1994;57: 383-6.

3. Schwartz CF, Grossi EA, Ribakove GH, Ursomanno P, Mirabella M, Crooke GA, et al. Ten-year results of folding plasty in mitral valve repair. Ann Thorac Surg. 2010;89:488-9.

http://dx.doi.org/10.1016/ j.jtcvs.2014.10.095

\section{ABOUT LEMONS AND LEMONADE}

To the Editor:

We read with great interest the article on lung volume reduction surgery (LVRS) published by Decker and coworkers, ${ }^{1}$ even though we found the results somewhat disappointing.

On one hand, the study provides a previously unknown nationwide overview on the early outcome achieved with LVRS, taking into account the Society of Thoracic Surgeons database data; Decker and coworkers ${ }^{1}$ underline that LVRS continues to be reportedly underused despite its proven efficacy and highlight the need to invest in future analyses to identify determinants of adjusted 